Journal of Contemporary Educational Research

Research Article

\title{
On English Adverbials: An English Teacher's View
}

Yaohuan Lu

Yantai Aihua Bilingual School, Yantai, Shandong Province, China

\begin{abstract}
For Grade two students in Senior High School, what is of vital importance is that students establish clear grammar networks at least after the second term to prepare themselves well for the firstround review of the third year and the following College Entrance Examination. With the scattered language points such as "with complex structure", "participles used as adverbials", or "absolute structure" learned by students in a gradual style, it is essential for them to clear out a main thinking path or thinking framework to make connections between knowledge points. The author finds in her years of teaching duration the relations between English adverbials, making it easier for students to know the know-how of learning English in a much scientific and reasonable way. Here are the findings.
\end{abstract}

Publication date: October, 2020

Publication online: 31 October, 2020

*Corresponding author: Yaohuan Lu, 1270245769@ qq.com

For Grade two students in Senior High School, what is of vital importance is that students establish clear grammar networks at least after the second term to prepare themselves well for the first-round review of the third year and the following College Entrance Examination $^{[1]}$. With the scattered language points such as "with complex structure", "participles used as adverbials", or "absolute structure" learned by students in a gradual style(Wang 2006) ${ }^{[2]}$, it is essential for them to clear out a main thinking path or thinking framework to make connections between knowledge points. The author finds in her years of teaching duration the relations between English adverbials, making it easier for students to know the know-how of learning English in a much scientific and reasonable way. Here are the findings. And this paper is all about the logic behind this
chart(Figure 1).

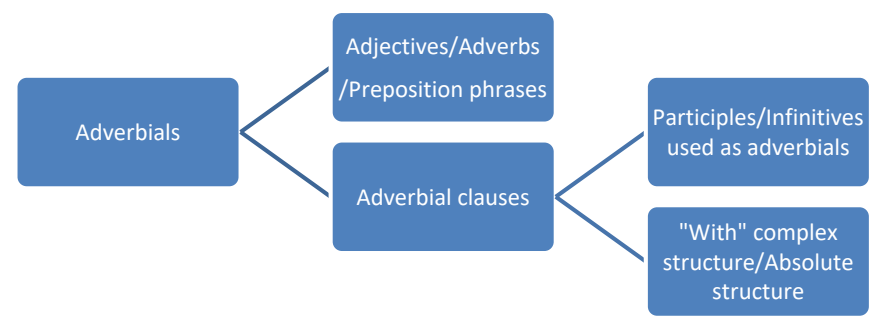

Figure 1. Relations between English adverbials

Firstly, the fundamentals composing the English adverbials are adjectives, adverbs, preposition phrases and adverbial clauses, the last one being the clauselevel adverbials that lead to much more advanced forms of adverbials, namely, non-predicate adverbials or other structures as adverbials. Here, these fundamentals compose the first-tier adverbials in the English language. Secondly, non-predicates, especially past and present participles, can be viewed as the predecessors of the adverbial clauses (Li 2015) which is what the definition and prerequisite of participles entail. Therefore, participles, either past or present ones, as well as infinitives are the second-tier adverbials, consisting of the more superior level. Thirdly, there being the third-tier adverbials, "With Complex Structure" and the "Absolute Structure", students are available to more advanced English expressions (Sanne 2018). Structures as they are, they are totally different from adverbial clauses which are after all with sentence structures, making it easier and more succinct to convey ideas and thoughts, the basic function of a language.

Need to say, it is essential to make distinctions between the internal factors of the three-tier adverbials. For instance, many English teachers hold the view that the "Absolute Structure" is the "With Complex Structure" without "With", a much easier way for students to understand and take in the usage of the 
seemingly complicated "Absolute Structure". As for the differences among the factors inside the first-tier and the second-tier adverbials, they are not the key and essentials for this paper, thus skipping them.

Clear about all the above basic concepts, the author can safely step into clarifying the use of "non-predicates used as adverbials", "with complex structure" and "absolute structure" used as adverbials. First and foremost, the prerequisite for "nonpredicates used as adverbials" is that they must share the same logical subject as the simple sentences (the main clause) with complete sentence structure do, while for "with complex structure" and "absolute structure", they both have their own logical subjects different from those of the completely-structured simple sentence (the main clause)(Wang 2006). To follow, English language sees that it has adverbial clauses that may either have the same subject as the main clause does or have a different subject within the sub-clause that has nothing to do with the subject of the main clause. With the first-tier adverbials (focusing on adverbials here) regarded as the fundamentals in the English adverbials, the second and third tiers can be considered as the variations and much advanced versions of adverbial clauses(Zhao 2012) ) $^{[3]}$. Last but not least, the relations between the second and third tier adverbials then require clarifying, meaning that once the functions of "with complex structure" and "absolute structure" are set clear, it must make sense for students to understand all the adverbials in English language. Easily seen, "with complex structure" and "absolute structure" require distinctive logical subjects from those of the main clause, while the non-predicate structures have the same subjects as the main clause, making it meaningful for students to understand totally the complicated relations between the English adverbials ${ }^{[4]}$.

However, that doesn't tell the whole story, given that the knowledge, if known by senior high students, helps them to see non-predicate structures, "with complex structure" and "absolute structure" from the viewpoints of English adverbials. If well-informed of the above chart beforehand, students are less inclined to mistake the relations among "participles used as adverbials", "with complex structure" and "absolute structure" since they actually share something in common(Toril 2011) ${ }^{[5]}$. What's more, just as routines of an English teacher, such a way of thinking may assist them in approaching the structures (the second-tier and third-tier structures used as adverbials) used as adverbials in the English language so as to make students take a broader and higher view before they jump into learning "non-predicates used as adverbials", "with complex structure" and "absolute structure", which are also used mainly as adverbials. In other words, seeing from the point of view of English adverbials, the approach of "non-predicates used as adverbials", "with complex structure" and "absolute structure" will become much briefer and simpler.

\section{References}

[1] Li ZX. On the Contraction of Adverbial Clauses[J]. China Training,2015(14):238.

[2] Wang JJ. Comparison of four English Adverbials and their Convertibility[J]. College English (Academic Edition),2006(02):50-53.

[3] Zhao QJ, Zhao QS. Journal of Qinghai University for Nationalities (social science edition), 2012, 38(4) : 135-138.

[4] Sanne VV, Janine B. Same difference? L1 influence in the use of initial adverbials in English novice writing[J]. International Review of Applied Linguistics in Language Teaching, 2018, 56(4).

[5] Toril S, Leiv EB. English Sentence Adverbials in a Discourse and Cognitive Perspective[J]. English Studies, 2011, 92(6). 